\title{
A CERTEZA E A SEGURANÇA COMO VALORES FUNDAMENTAIS NA DECLARAÇÃO DO DIREITOO E NA REALIZAÇÃO DA JUSTIÇA, E O MODO DE ATINGI-LAS
}

\author{
Custódio da Piedade Ubaldino Miranda \\ Professor Doutor do Departamento de Direito Civil da \\ Faculdade de Direito da Universidade de São Paulo
}

\begin{abstract}
Resumo:
$\mathrm{O}$ artigo pretende demonstrar que as decisões judiciais devem nortear-se, na declaração do direito, no caso concreto, que resultará sempre do que abstratamente se acha previsto nas normas legais, quer de direito material, quer de Direito Processual, aplicadas mediante prévia interpretação teleológica e sistemática das mesmas, pelos princípios gerais da Ciência do Direito, que serão as válvulas de controle da correta aplicação daquelas normas que regerão o mesmo caso concreto. Com isso, alcançar-se-á não-só a realização da Justiça, entendida esta como a prevalência, legalmente fundamentada, de um dos interesses conflitantes em detrimento do outro, mas também a certeza e a segurança jurídicas, valores intimamente ligados ao da Justiça, com a conseqüente uniformização da jurisprudência, além do mais. Procurou-se ilustrar as idéias expendidas com comentários a dois acórdãos de tribunais diferentes do Estado de São Paulo.
\end{abstract}

\begin{abstract}
:
The article intends to show that, in the declaration of law in the concrete case, which will always result from that which is provided in an abstract manner in the legal rules whether of material or Procedural Law, enforced through prior teleological and systematic interpretation of same, the court decisions should guide themselves by the general principles of the science of law, which will be the control valves for the correct enforcement of the same legal rules which shall govern the same concrete case. Thus, not only will Justice be achieved, which is to be understood as the lawfully founded prevalence of one of the conflicting interests to the detriment of the other, but also legal certainty and security, which are values intimately related to the value of Justice, with the consequent uniformity of case law, apart from everything else. An attempt was also made to illustrate the ideas put forward with comments on two decisions held by two different high courts in the State of São Paulo.
\end{abstract}

Unitermos: decisões judiciais: aplicação dos princípios gerais; realização da Justiça; certeza e segurança jurídicas, uniformização da jurisprudência. 
O que nos propomos tratar aqui é mostrar como e porque as decisões judiciais deverão nortear-se, na declaração do direito e na realização da Justiça, por critérios científicos, mais precisamente, porque as decisões judiciais haverão de se fundamentar mediante a aplicação das normas legais, atinentes ao caso concreto, e dos princípios gerais que constituem verdadeiras conquistas da Ciência do Direito, princípios, na sua maioria, velhos de séculos, mas sempre revitalizados à luz do que vão desvendando os doutrinadores, no seu paciente labor de investigação científica.

Vêm estas considerações, a propósito do fato, de que dificilmente isso ocorre na maioria das decisões judiciais de nossos juízes e tribunais, especialmente ao nível dos tribunais inferiores, salvo exceções que sempre existem, não-só nos tribunais deste Estado, mas também, e até em maior número, nos do Sul do País, até mesmo quando alcançam resultados satisfatórios na resolução dos conflitos de interesses.

Uma fundamentação convincente pode até desencorajar a parte vencida a recorrer, com o que poderá contribuir-se para o descongestionamento do acúmulo dos processos, com todas as vantagens inerentes. Todavia, e não-obstante, dificilmente os tribunais reconhecem que suas decisões são passíveis de crítica, por forma a que o que já foi decidido possa vir a ser modificado, embora reconheçam até, por vezes, a consistência dos argumentos que lhes são apresentados, em sentido contrário, aferrados, por exemplo em matéria dos embargos de declaração, à idéia de que eles não devem ter caráter infringente.

Embora a jurisprudência do próprio Superior Tribunal de Justiça já tenha reconhecido, por um lado, que eles se destinam ao aprimoramento da prestação jurisdicional e que os juízes não devem vê-los como crítica ao seu trabalho, mas como instrumento de aperfeiçoamento das suas decisões, e, por outro, que os embargos de declaração podem, em certos casos, ter efeitos infringentes e, como tal, modificar até o julgado, pode se dizer que, não-obstante, rarissimamente, só quando se tratar de erro notoriamente grosseiro os embargos surtem aquele efeito modificativo.

Comentaremos, à luz destas considerações, duas decisões, proferidas por tribunais diferentes deste Estado.

Recentemente, numa decisão de uma das Câmaras do Egrégio Segundo Tribunal de Alçada Civil deste Estado, o juiz relator, acompanhado pelos demais membros da Câmara, chegou a afirmar textualmente no acórdão proferido em embargos: 
"A conclusão do acórdão pode não ser tão-evidente, mas, 'data venia', deve prevalecer" sendo que anteriormente se afirmara: "os argumentos da recorrente foram muito bem expostos, mas esbarram com a lógica"

E qual era essa lógica? É necessário, antes do mais, saber qual era o caso que se julgava.

Tratava-se de um agravo de instrumento, interposto pela exeqüente, do despacho que, mui lógica e coerentemente, indeferira a extração da carta de sentença, porque a apelação, interposta pela executada da sentença proferida nos embargos à execução, havia sido recebida "nos seus regulares efeitos" A exeqüente não-recorreu do despacho, deixando-o transitar em julgado, mas requereu a extração da carta de sentença para iniciar a execução provisória, que foi indeferida, precisamente porque a apelação havia sido recebida, como o disse expressamente o magistrado, "em ambos os efeitos"

A exeqüente agravou deste último despacho, com o fundamento de que os embargos haviam sido julgados parcialmente procedentes e que, tendo ela decaído em parte mínima, "significa que há parte substancial dos embargos que foi julgada improcedente e, quanto à esta parte, com certeza, só pode haver efeito devolutivo ao apelo interposto"

Deixaremos para logo mais a crítica à lógica simplista desta argumentação, infelizmente acolhida pelo acórdão, para apontar, antes do mais, dois graves equívocos em que, em nosso entender, ele incorreu e que, não-obstante tacitamente reconhecidos, assim o cremos, não produziram qualquer efeito nos embargos de declaração.

O primeiro é o de ter permitido reabrir-se a discussão sobre uma questão já decidida, ou seja, os efeitos da apelação da sentença que julga os embargos parcialmente procedentes, afastando pura e simplesmente a incidência, no caso, do art. 473 do Código de Processo Civil que dispõe: "É defeso à parte discutir, no curso do processo, as questões já decididas, a cujo respeito se operou a preclusão"

Nem se diga, como se fez no acórdão, que "o recurso é tempestivo, porque a embargada não podia recorrer da decisão que recebeu a apelação 'em seus regulares efeitos' Se ela entendia que só o efeito devolutivo seria regular, não se podia sentir prejudicada pela decisão. Só ocorreu gravame quando o magistrado declarou que 'regulares' eram ambos os efeitos" 
Nada justifica esta conclusão. Antes de mais, não cabe aos tribunais defender a interpretação de uma decisão ou de um despacho, de uma das partes. A sua missão constitucional é a de interpretar a lei para declarar o direito para o caso concreto, supra partes. Nessa tarefa, cumpre-lhe apenas dizer se a interpretação que a parte deu a uma determinada decisão ou despacho está ou-não correta, em face da lei.

Por outro lado, não se diga também que a lei deve ser humanamente interpretada $^{1}$ e que o rigor da lei, ou seja, a consagração do instituto da preclusão, pode ser relevado na medida em que atende ao interesse de uma das partes, precisamente aquela que venceu a demanda, na sua maior parte. Este argumento confunde-se com o próprio mérito do agravo de instrumento e por isso será tratado mais adiante. Mas há que notar, desde logo, que haveria, nessa conclusão, uma abordagem meramente emocional, já que nenhum argumento racional justifica que se chegue a uma tal conclusão.

Mais ainda, basta dizer que a realização da Justiça supõe sempre, e a isso se limita, ${ }^{2}$ um conflito de interesses, dos quais um terá necessariamente de ser sacrificado em benefício do outro. Quando as coisas se colocam deste modo, logo se vê que só uma correta declaração do direito, no caso concreto, vai dizer se é justo que se sacrifique o interesse do executado ao do exeqüente, já que os dois interesses são conflitantes: este tendo o interesse numa imediata execução da sentença, aquele tendo um interesse contrário, de que isto só se faça após o julgamento da apelação.

Por aqui se vê também que declarar o direito, com acerto, a partir da correta aplicação, mediante prévia interpretação (teleológica e sistemática) das normas legais, além de conferir um certo grau de certeza e segurança às relações jurídicas (cada um passa a saber em que lei vive, com que bens pode contar e quais os planos de futuro que pode traçar), contribui para a própria realização da Justiça, como acima se viu, até mesmo porque aquele, cujo interesse é sacrificado, acaba por se convencer de que aquela era a única solução possível, à luz do ordenamento jurídico vigente.

A humanização da lei, ao que nos parece, só tem sentido quando, na solução desse conflito, a declaração do direito, resultante da aplicação dos preceitos

1. Luis Recasens Siches, Nueva Filosofia de la Interpretacion del Derecho, México, Editorial Porrúa S.A., 1973.

2. Hans Kelsen, $O$ que é Justiça? tradução de Luís Carlos Borges, São Paulo, Martins Fontes, 1997. 
legais, conduza a uma injustiça, no sentido de que fira o sentimento da Justiça, nãosubjetivo ou pessoal do juiz, mas da própria comunidade em que se acha inserido, e de que ele será o intérprete por excelência. Enquanto isso não-ocorre, a declaração do direito deve resultar apenas do que dispõem as normas como parte de um sistema, o que quer dizer que há que interpretá-las corretamente, de acordo com os cânones da hermenêutica e atendendo aos fins sociais a que ela se destina (art. $5^{\circ}$ da Lei de Introdução).

Um segundo equívoco do acórdão foi o de admitir um agravo de o despacho que, em nosso entender, era de mero expediente. Na verdade, se os efeitos da apelação já haviam sido fixados anteriormente, em verdadeira decisão interlocutória, em que foi necessário se formar um juízo prévio, ainda que nãoexpresso, sobre o verdadeiro sentido e alcance de uma norma legal, o citado art. 520 e seu inciso V, do Código de Processo Civil, o despacho que se the seguiu, indeferindo a extração da carta de sentença, nada mais era do que uma sua conseqüência, não envolvendo qualquer juízo de valor e conseqüentemente não apresentando qualquer conteúdo decisório.

Posto isto, voltemos ao cerne da discussão, a questão de saber se os "regulares efeitos" de uma apelação da sentença, que julga os embargos parcialmente procedentes, são "ambos os efeitos" o suspensivo e o devolutivo, ou só o devolutivo.

A lógica do acórdão, quando declara que, se a lei confere à apelação da sentença que julga os embargos à execução improcedentes apenas o efeito devolutivo, meramente devolutivo será também o efeito dos embargos julgados parcialmente procedentes, na parte abrangida pela improcedência (lógica, aliás, do exeqüente, apoiada pela Câmara julgadora), é totalmente insustentável, em nossa opinião, por razões que se passa a expor.

Trata-se de uma conclusão simplista, de uma lógica à primeira vista consistente, no plano do raciocínio comum, mas que não se agüenta nos domínios do pensamento jurídico, que deve sempre ser norteado pelos princípios gerais a que acima se referiu. Em suma, aqui só se deve recorrer à lógica jurídica.

Os efeitos da apelação estão dispostos no art. 520 do Código de Processo Civil, em que se lê: 
Será, no entanto, recebida só no efeito devolutivo, quando interposta da sentença que: "V rejeitar liminarmente os embargos à execução ou julgá-los improcedentes.

Daqui se vê que há um efeito normal (ambos os efeitos, o suspensivo e o devolutivo) e um efeito excepcional (só o efeito devolutivo) da apelação, ou seja, a regra geral é a de que interposta a apelação ela suspende os efeitos da sentença até que seja julgada, além do que "devolve" à apreciação do Tribunal toda a matéria da apelação (tantum devolutum quantum apellatum) e a regra excepcional é a de que em certos casos (assim, a rejeição liminar dos embargos e a sua total improcedência) a apelação tem apenas este último efeito, não suspendendo os efeitos da sentença.

Mas a lei nada diz quanto ao caso dos embargos julgados parcialmente procedentes, nem se pode concluir que esta hipótese esteja contemplada no espírito do citado inciso $\mathrm{V}$. por forma a poder se dizer que ele deve ser interpretado extensivamente, estendendo-se àquela hipótese a disciplina da sentença que julga os embargos improcedentes. Decididamente, a lei nãocontemplou tal hipótese, nem na letra nem no espírito do citado inciso V, podendo mesmo se dizer que a omitiu deliberadamente do âmbito daquele inciso, precisamente por se tratar de uma situação diferente da dos embargos julgados improcedentes.

Trata-se assim de uma hipótese omissa, não contemplada na lei, de uma lacuna, que terá de ser integrada com os métodos de integração da lei, prescritos no art. $4^{\circ}$ da Lei de Introdução ao Código Civil, o primeiro dos quais é a analogia. Poderá aplicar-se por analogia a regra do citado inciso V. editada para o caso dos embargos julgados improcedentes ao caso dos embargos julgados parcialmente procedentes?

A doutrina tradicional sustenta que não, e o argumento baseia-se no seguinte raciocínio: se o legislador não quis apartar uma determinada situação fática para lhe dar um tratamento excepcional, é porque quis sujeitá-la à incidência da regra geral. Logo, a nossa hipótese (embargos julgados parcialmente procedentes) estaria contemplada implicitamente na regra geral do caput do art. 520 .

Todavia, esse raciocínio tem sido questionado pela doutrina moderna com o argumento de que pode haver situações em que o legislador não tenha contemplado nem na regra nem na exceção, tratando-se de casos verdadeiramente omissos e que nada impede que, nessas condições, a regra excepcional seja aplicada, 

realização da Justiça, e o modo de atingi-las

por analogia, desde que se verifiquem os pressupostos desta aplicação, ou seja, se descubra uma relação de semelhança entre o caso omisso e o caso previsto.

"De feito, considerada, numa noção geral, a analogia como a aplicação de uma regra de direito, reguladora de certas e determinadas relações, a outras relações, que têm semelhança ou afinidade com aquelas, mas para as quais não está ela estabelecida, pode-se repetir que esse processo tem por fundamento a identidade da ratio legis, inspirando-se no princípio que, onde existe a mesma razão de decidir, deve-se aplicar o mesmo dispositivo de lei - ubi eadem legis ratio, ibi eadem legis dispositio" 3

Se assim é, pode-se perguntar: procedem para o caso omisso (embargos julgados parcialmente procedentes) as razões que levaram o legislador a estatuir o efeito meramente devolutivo para o caso previsto (embargos julgados improcedentes)?

Parece-nos que não, pelas razões que se passa a expor:

Quando a sentença julga os embargos improcedentes ou os rejeita liminarmente, compreende-se que a apelação não tem efeito suspensivo, já que a sentença anterior, proferida no processo de conhecimento, sendo um título executivo judicial, revestido da força e da autoridade de coisa julgada, só é impugnável por via dos embargos nas hipóteses taxativas do art. 741 do Código de Processo Civil, isto é, a matéria dos embargos é restrita à "pretensão nascente de vício processual que torna nula ipso iure a decisão, sem qualquer atinência ao seu conteúdo decisório" 4

Ora, se essa impugnação não foi atendida e os embargos são julgados improcedentes (ou rejeitados liminarmente), admite-se desde logo a execução provisória, pois nessas circunstâncias, entre os dois interesses conflitantes, o do exeqüente, de ver iniciada de imediato a execução e o do executado, de vê-la suspensa, prevalece aquele, até mesmo porque há uma probabilidade de que a sentença seja confirmada, porque a averiguação da existência dos vícios meramente

3. Eduardo Espinola e Eduardo Espinola Filho, A Lei de Introdução ao Código Civil Brasileiro, atualizada por Silva Pacheco, Rio de Janeiro, Renovar, 1995, v. I, p. 104.

4. Celso Neves, Comentários ao Código de Processo Civil, $4^{\mathrm{a}}$ ed., Rio de Janeiro, Forense, 1992, v. VII, pp. 266-267. 
processuais funda-se mais em operações de mera constatação, do que propriamente em considerações de mérito, que envolvam juízos de valor.

Já não se pode dizer o mesmo quando os embargos são julgados parcialmente procedentes.

Aqui, a sentença acena com a possibilidade de, em grau de apelação, ser ampliado o benefício conquistado pelo executado na ação dos embargos e não é justo que não se lhe conceda a oportunidade de ver a sua defesa, já parcialmente vitoriosa na primeira instância, apreciada e decidida, em grau de apelação, sem que, entretanto, corra o risco de ver iniciada contra si uma apressada execução, movida pelo credor. A Justiça aqui, a que acima se referiu, também redunda afinal na prevalência que se deve dar, entre os dois interesses conflitantes, a um deles, neste caso ao do executado.

É por isso que o legislador não terá contemplado a situação que vem ser discutida na exceção do inciso V. mas na regra do caput do art. 520 .

Aliás, uma interpretação sistemática do citado inciso $\mathrm{V}$ do art. 520 conduz à mesma conclusão.

Com efeito, a regra excepcional do inciso $\mathrm{V}$ deve ser de aplicação restrita às situações nela previstas porque só uma interpretação dessa natureza pode considerar-se conforme à Constituição, mais precisamente ao preceito contido no seu art. $5^{\circ}$, inciso LV, segundo o qual "aos litigantes, em processo judicial ou administrativo, e aos acusados em geral são assegurados o contraditório e ampla defesa, com os meios e recursos a ela inerentes" Efetivamente, o direito do contraditório e da ampla defesa não seria respeitado numa situação em que, estandose em dúvida sobre o efeito da apelação por se tratar de uma hipótese não prevista na lei expressamente, se optasse por aquela em que tal direito fosse reconhecido sim (dir-se-ia, não se tirou tal direito do executado tanto assim que ele apelou), mas com um maior gravame para quem apela.

A interpretação de uma norma deve ser sempre teleológica, há que se atender aos juízos de valor legais e parece intuitivo que se a hipótese em questão (embargos julgados parcialmente procedentes) não foi contemplada no inciso $\mathrm{V}$ é porque a lei sujeitou a situação à regra geral. Há aqui uma perfeita coincidência entre a conclusão a que se chega (por outros motivos e caminhos) e o pensamento da doutrina tradicional, da inaplicabilidade, por analogia, das regras excepcionais.

Nem se diga que a aplicação dos princípios gerais, que constituem a base e o conteúdo da ciência do Direito, faz-nos incorrer no vício do conceitualismo, 
que procurava deduzir dos conceitos as soluções para os casos concretos da vida, quando o que importa são os interesses a serem regulados e as soluções legais com base nas quais devam sê-lo, podendo os conceitos serem formulados apenas a partir dessas soluções, razões essas pelas quais o método conceitual está definitivamente erradicado da Ciência Jurídica. É certo que o que se procura é resolver os conflitos de interesses, saber qual dos dois interesses conflitantes deve afinal prevalecer, mas não é menos certo que isto só pode ser feito, por via racional, pela declaração do direito, no caso concreto, a partir do que se acha abstratamente previsto nas normas que formam o sistema e com a racional observância dos mandamentos ali contidos.

As decisões assim emitidas, como já se disse e nunca é demais repetir, além de oferecerem uma grande margem de certeza e segurança aos jurisdicionados, contribuem, sem dúvida, para a uniformização do Direito, na medida em que os juízes não se afastam dos princípios gerais, deixando, ainda, pouca margem para recursos impertinentes, que assoberbam sem motivo os tribunais.

Por outro lado, a certeza e a segurança, vistas assim as coisas, são valores intimamente ligados ao da Justiça, na medida em que uma decisão proferida à base das normas jurídicas que dispõem sobre a atribuição dos bens, sejam eles de que natureza for, e mediante a aplicação dos princípios gerais da Ciência Jurídica, acabará por convencer a própria parte vencida de que o caso concreto não poderia ser decidido de outro modo; por outras palavras, uma decisão que se funde em dados objetivos e racionais e que não seja produto de uma visão puramente subjetiva e pessoal do juiz (não se ignora que haverá sempre um certo grau de subjetivismo nas decisões na medida em que a própria avaliação dos dados objetivos é feita por alguém que tem a sua própria concepção do mundo e da vida, mas isto é outra coisa) terá uma força de convicção a que dificilmente poderá resistir-se.

A título ilustrativo, apontaremos agora uma outra decisão que, se fosse proferida com a aplicação dos princípios gerais e conseqüentemente sustentada com fundamentação erigida naqueles princípios e na estrita aplicação das normas legais, além de prestar um relevante serviço à certeza e à segurança jurídicas, lograria convencer as partes em litígio, especialmente a parte vencida, de que era uma decisão justa, de que não havia outra solução para o caso, senão a de sacrificar aquele interesse conflitante, por razões consistentes, em face das normas legais e dos princípios gerais, aplicáveis ao caso.

Tratava-se de uma liquidação em cujo processo foi proferida sentença que, sob fundamento de que interpretava o acórdão proferido em processo de 
conhecimento, alterou, em nosso entender, substancialmente a decisão nele contida, com frontal violação do disposto no art. 610 do Código de Processo Civil, que proíbe expressamente que, na liquidação, se modifique o julgado.

O acórdão em questão, interpretando e integrando os pedidos contidos na petição inicial, esclareceu o que não havia ficado claro na sentença e proferiu o seguinte decisum:

"Adotadas essas premissas é a paleação dos autores provida para a condenação solidária pelas perdas e danos decorrentes da inexecução contratual de $C$ e B. As perdas e danos, na forma do pedido inicial, compreendem o pagamento das importâncias desembolsadas para a formalização do loteamento (fl. 11), os prejuizos resultantes da indisponibilidade da propriedade imobiliária, em razão do contrato inadimplido, tudo como se apurar em execução, juros de mora a partir da interpelação (fl. 88) e correção monetária a partir da edição da Lei $n$. 6.899, de 1981"

Apresentemos, em síntese, o histórico do caso. Os autores, proprietários de um imóvel, constituído de duas glebas de terras, compromissaramno à venda à ré $\mathrm{B}$, uma empresa de engenharia e terraplanagem, a qual se comprometera a implantar no imóvel um loteamento, sendo que o preço do imóvel seria pago aos autores parte em dinheiro e parte com o rateio, na proporção de $50 \%$ para cada uma das partes, entre os autores e a ré, do produto da venda dos lotes, assim valorizados com o loteamento. Houve também a intervenção de um banco que, numa operação triangular, garantia o negócio, não interessando aqui entrar nos detalhes dessa operação.

O que interessa, para o efeito do nosso estudo, é salientar que o contrato não foi cumprido pelo réu, houve uma ação com pedido de rescisão do contrato, cumulado com perdas e danos, movida pelos autores, a ação foi julgada procedente, mas em apelação os autores obtiveram a condenação solidária do banco, por a douta Câmara julgadora ter entendido que havia uma evidente comunhão de interesses entre a ré e o banco e tal condenação ter sido pedida expressamente na inicial. A certa altura os autores desistiram da ação contra a empresa de engenharia, já inexistente e insolvente, prosseguindo-a apenas contra o banco.

A condenação em perdas e danos, tal como havia sido pedida na inicial, foi genérica na sentença, mas o tribunal, como acima se disse, interpretando e 

realização da Justiça, e o modo de atingi-las

até integrando o pedido inicial, houve por bem traçar os limites exatos dessa condenação: "a. o pagamento das importâncias desembolsadas para a formalização do loteamento; $b$. os prejuízos resultantes da indisponibilidade da propriedade imobiliária em razão do contrato inadimplido, tudo como se apurar em execução, juros de mora a partir da interpelação e correção monetária a partir da edição da Lei $n .699$ de 1981".

Os autores não-interpuseram embargos de declaração dessa decisão para suprir qualquer omissão eventualmente nela contida, nem interpuseram recurso especial para enfrentarem uma eventual reformatio in pejus, mas iniciaram a liquidação que, em nosso entender, já excedia os limites dessa condenação, na medida em que requereram o valor correspondente a $50 \%$ do produto da venda dos lotes, caso tivesse sido efetuada, de acordo com o contrato.

$\mathrm{Na}$ contestação o réu, como se disse, agora só o banco, contestou a ação, afirmando que tal pedido não era fundado no título executivo, uma vez que o acórdão citado, transitado em julgado, só concedera: a. o pagamento das importâncias efetivamente desembolsadas pelos autores para a formalização do loteamento e b. o valor dos prejuízos sofridos pelos autores por terem ficado com o imóvel, compromissado à venda à empresa ré para a implantação do loteamento, indisponível, durante o período em que estivera compromissado.

A r. sentença julgou a liquidação procedente, concedendo aos autores os $50 \%$ pleiteados, além da rescisão do contrato, mas o que mais surpreende é que ela foi confirmada pelo acórdão, com os fundamentos que a seguir serão analisados.

$O$ acórdão, que vem de se comentar, confirmando a sentença que negara a indenização pela indisponibilidade do imóvel, por não-comprovada, começou por afirmar (confirmando a sentença também nesta parte) que a indenização pelo não-cumprimento do contrato deveria corresponder ao que nele fora acordado e, portanto, ao equivalente aos $50 \%$ do produto da venda dos lotes, caso o imóvel tivesse sido loteado; e mais: que pouco importava que o acórdão exeqüendo, na cognição do recurso dos autores, a que deu provimento para incluir o banco apelante na condenação, houvesse feito quanto à extensão das perdas e danos, referências passíveis de serem interpretadas como limitações teóricas ao objeto da liquidação. Tratar-se-ia, de obiter dicta, de motivação da decisão, que não faz coisa julgada (quando é claro e inquestionável, como se vê da transcrição acima, que se tratava da parte dispositiva e que faz coisa julgada) sem nenhuma relevância ou repercussão nos limites objetivos da coisa julgada, pois não tendo dado provimento 
ao recurso do réu, "não podia nunca, com validez e eficácia, ter restringido a largueza da condenação, prejudicando os recorrentes, pois caracterizar-se-ia, manifestíssima (sic) reformatio in pejus". A condenação contida na sentença é que seria, segundo o acórdão, matéria coberta pela res iudicata.

Não estamos de acordo com a fundamentação deste acórdão, por mais de uma razão, e isso independentemente do fato de se apurar se pode ocorrer reformatio in pejus, quando o acórdão limita-se, interpretando e integrando a sentença, no que ela tem de obscuro e de omisso, a alterar aparentemente o que ela estabelecera, sem que o seja em decorrência do recurso de qualquer das partes. É que a sentença não-lançara quaisquer parâmetros para a quantificação da indenização, nem sequer dissera qual a natureza e a espécie dos danos ressarcíveis, não-cumprindo adequadamente a prestação jurisdicional, própria da ação de conhecimento em matéria de perdas e danos.

Neste sentido, ao que nos parece, o magistério do eminentíssimo Pontes de Miranda, quando escreve:

"Se a sentença atingiu todos os assuntos do pedido e houve a apelação, mesmo quanto a todas as partes da sentença, há a hipótese de haver questões a que a lei atribua a examinabilidade e julgamento de ofício, e que pelo juiz recorrido não foram julgados; e a hipótese de haverem sido postos no pedido e não estarem na sentença apelada. Quanto à primeira hipótese, pensemos em se tratar de incidência de lei (quaestiones iuris), e não poderia o órgão ad quem deixar ignorar a lei e fugir à sua missão de prestar o que o Estado prometeu com a sua tutela jurídica" (Comentários ao Código de Processo Civil, Rio-São Paulo, Forense, 1975 , t. VII, p. 214).

Mas o que é mais importante saber é que o acórdão que vem se examinando decidiu soberanamente contra a lei e os princípios gerais, que a reformatio in pejus (ainda que se suponha ter havido), contida no acórdão proferido na ação de conhecimento, quando, interpretando a sentença, definiu claramente os limites da condenação (no dizer do acórdão ora comentado, restringindo os limites da sentença anteriormente fixados), acarreta uma nulidade de pleno direito de tal modo que não foi necessária qualquer alegação nesse sentido da parte prejudicada, que, como se disse, não-interpôs embargos de declaração ou recurso especial para se insurgir contra tal situação, incorrendo o acórdão no absurdo de cometer uma 
flagrante ilegalidade, impedindo que a liquidação guardasse fidelidade ao título executivo, ou seja, ao acórdão, proferido na ação de conhecimento, como o preceitua a lei.

Com efeito, é sabido que o regime das chamadas nulidades absolutas, ou de pleno direito, como também são conhecidas, é determinado por motivos de interesse público, é destinado a salvaguardar o interesse público; enquanto as nulidades relativas são estabelecidas por motivos de interesse particular, destinam-se à salvaguarda do interesse particular de certas pessoas. ${ }^{5}$

Se assim é, logo se vê que a proibição da reformatio in pejus (que nãoresulta, aliás, de qualquer disposição expressa do ordenamento processual, mas sendo consagrada pela unanimidade da doutrina e da jurisprudência), cujo conceito está ligado ao agravamento da posição do recorrente que se vê numa situação mais desfavorável por força do recurso com que pretendeu beneficiar-se, não-envolve senão o interesse particular do mesmo recorrente em não ser mais prejudicado do que já está por força da decisão de que recorre, precisamente para melhorá-la.

Tendo o acórdão, prolatado na ação de conhecimento, transitado em julgado, ainda que viciado de uma reformatio in pejus, teria de prevalecer, não podendo, como foi, ter sido alterado inicialmente por uma sentença, emanada de um juízo inferior e posteriormente por um colegiado, de igual nível, é verdade, mas sem obediência à lei e aos princípios gerais de que vimos falando, com grave prejuízo da certeza e segurança jurídicas e da própria Justiça, como se vai ver.

Com efeito, desta forma, sacrificou-se o interesse do réu arbitrariamente, não porque o ditavam as leis e os princípios em vigor. Praticou-se a reformatio in pejus, agora em prejuízo do réu, sem que nada o justificasse, e deste modo cometeu-se para com este uma injustiça. Como acima dissemos, a realização da Justiça envolve a resolução de um conflito de interesses, dos quais um terá necessariamente de ser sacrificado e para saber qual deles deverá sê-lo só se poderá atuar, para se garantir a necessária objetividade e a certeza e a segurança jurídicas a que nos referimos, a partir do que estabelecem as normas legais e os princípios gerais aplicáveis ao caso a decidir.

As perdas e danos destinam-se, como se sabe, a recompor o patrimônio do credor, lesado com o inadimplemento da obrigação; não visam recriar

5. Manuel Domingues de Andrade, Teoria Geral da Relação Jurídica, Coimbra, Almedina, 1992, v. II, pp. 415-416. 
o cumprimento das obrigações que não foram executadas, nem se destinam a ser uma fonte de enriquecimento ou de lucro à custa do devedor. Tal recomposição, no caso, uma vez que, em virtude da rescisão do contrato, o imóvel fora reintegrado na posse dos autores, só podia ocorrer, como muito bem o decidira o acórdão prolatado na ação de conhecimento, mediante o reembolso de quantias eventualmente desembolsadas pelos autores para a implantação do loteamento e pela atribuição de uma quantia a ser paga, pela indisponibilidade da propriedade imobiliária pelo tempo em que ficou na posse da ré.

Nisso consistiria uma autêntica indenização, quando acrescida à rescisão do contrato, uma vez que os autores voltaram a ter a posse do imóvel compromissado, não se operando, portanto, a transferência do domínio do mesmo em virtude da rescisão do contrato. É esta a conclusão a que conduzem as normas legais e os princípios gerais aplicáveis ao caso, e o sentimento do justo não-discrepa de tal resultado, precisamente porque a Justiça se alcança e se realiza com a declaração do direito, captado este através daquelas mesmas normas legais e princípios gerais aplicáveis.

Concluindo: por aqui se vê que não deve o juiz, na elaboração da sentença, seguir aquele "método", a que se referia um certo autor como sendo o utilizado atualmente pelos magistrados, por contraposição ao raciocínio subsuntivo e de pura lógica formal a que aludiam os exegetas, e que é o seguinte: o juiz, ao ensejo da elaboração da sentença, finda a leitura do processo, já tem a idéia da decisão que vai proferir, de acordo com o seu próprio sentimento de Justiça (absolutamente subjetivo e pessoal, portanto) e em seguida procura (e nós acrescentaremos, às vezes a todo o custo, se possível com base na lei, sem se importar muito com a correção da sua interpretação, não-obstante disto resultar o acerto da decisão) a fundamentação.

Parece-nos que o caminho deve ser o inverso, com o que não se está fazendo apologia da teoria subsuntiva ou da lógica formal. Toda a decisão deve ser lógica, é certo, mas deve estar sustentada numa lógica jurídica, na medida em que terá de ser proferida à luz dos preceitos legais, de todos os preceitos, quer de direito material, quer de Direito Processual, que regem a matéria, objeto de análise, mediante uma prévia interpretação teleológica e sistemática daqueles preceitos, pelo que ela redundará na declaração do direito e na realização da Justiça, no caso concreto, mediante a prevalência de um dos interesses conflitantes e o sacrifício do outro, valorados à luz daqueles preceitos e princípios, assim aplicados. 

realização da Justiça, e o modo de atingi-las

Com isto, quer nos parecer, alcançar-se-á a realização dos valores fundamentais que o Direito persegue: a Justiça, a certeza e a segurança jurídicas, sua própria uniformização, etc.

São Paulo, 11 de janeiro de 1999. 